\title{
IS en zijn voorgangers: gewelddadig radicalisme in historisch perspectief
}

\author{
B.G.J. de Graaff
}

Zo'n negentig jaar nadat het islamitische kalifaat ten einde kwam, riep Aboe Bakr al-Baghdadi op 29 juni 2014 in Mosul een nieuw, wereldwijd, kalifaat uit. Met deze proclamatie wekte de top van Islamitische Staat (IS) bij een deel van de moslims wereldwijd een gevoel van herwonnen trots na een lange periode van vernedering en achterstelling. Deze lokroep leidde tot een grotere stroom jihadgangers dan bij voorafgaande jihadistische conflicten. Wat was de toverformule waarmee dit IS lukte? IS benadrukt in zijn communicatie dat het kalifaat zich bevindt in het gebied dat volgens islamitische voorstellingen de locatie van de eindstrijd tussen goed en kwaad en de vestiging van het heilsrijk zal zijn. Het internettijdschrift van de beweging, dat in verschillende talen verschijnt, heet bijvoorbeeld Dabiq, genoemd naar de plaats waar die finale afrekening tussen de heerscharen van goed en kwaad zal plaatsvinden, een plaats die ook in handen is van IS. IS is ook een mengeling van het uitmeten van slachtofferschap van moslims en het uitventen van gruwelijk geweld tegen andersdenkenden. Anders gezegd: slachtofferschap rechtvaardigt daderschap. Deze vorm van counter-humiliation is bij uitstek een formule die bij apocalyptische bewegingen in zwang is: aan het einde der tijden zullen de eersten de laatsten zijn en de laatsten zullen de eersten worden. Dit is dus niet nieuw. Het gaat om de gebruikmaking van een verhaal waarin een heilsrijk als laatste stadium van de geschiedenis wordt verkondigd, een narratief waarmee wordt aangezet tot het gebruik van geweld. IS bedient zich van verhaalelementen die al eeuwenlang worden benut om mensen aan te zetten tot het gebruik van geweld om een heilsrijk

* Prof. dr. Bob de Graaff is hoogleraar inlichtingen- en veiligheidsstudies aan de Nederlandse Defensieacademie te Breda en de Universiteit Utrecht. Van 2007 tot 2009 was hij hoogleraar terrorisme en contraterrorisme aan de Campus Den Haag van de Universiteit Leiden, waar hij het Centrum voor Terrorisme en Contraterrorisme (CTC) oprichtte. 
naderbij te brengen, of het nu gaat om christelijke, seculiere of islamitische varianten (De Graaff 2012).

\section{Apocalyptici in soorten en maten}

Verhalen over zo'n eindrijk zijn van alle windstreken en alle geloofsovertuigingen. Ze komen dan ook al duizenden jaren voor. Zulke apocalyptische verhalen beloven een einde der tijden waarin de goede elementen eindelijk zullen winnen van de krachten van het kwaad en vervolgens een definitieve heilsstaat wordt bereikt. In religieuze varianten van dit apocalyptische verhaal is het God die een heilsplan met de mensheid voorheeft en ingrijpt in de aardse poel van ellende. In seculiere varianten neemt de geschiedenis, hetzij door menselijk handelen, hetzij door collectieve krachten, een loop naar een definitieve toestand die zaligmakend is (De Graaff 2012).

$\mathrm{Nu}$ is het niet zo dat alle apocalyptici gewelddadig zijn. In grote lijnen kan men vier groepen onderscheiden (De Graaff 2012, p. 19-20). De eerste groep vindt dat de mens de bepaling van het einde der tijden moet overlaten aan God of het verloop van de geschiedenis. Men zou hen de deterministen kunnen noemen, met een verwijzing naar Marx, die meende dat een aantal economische stadia moest worden doorlopen voordat het stadium van de bourgeoisie plaats zou maken voor de uiteindelijke heilzame dictatuur van het proletariaat.

Een tweede groep is van oordeel dat mensen weliswaar geen invloed hebben op het moment waarop het paradijselijke einde der tijden zich aandient, maar dat zij wel kunnen proberen met kleine stapjes en goede daden een eind op te schieten in de gewenste richting. We zouden hen de reformisten kunnen noemen.

Een derde groep meent dat de wereld zo verdorven is dat het een illusie is haar als mensen beter te kunnen maken. Goedgezinden kunnen echter wel in afzondering van de boze wereld proberen met elkaar een zo paradijselijk mogelijke voorafspiegeling van de heilsstaat te creëren. Dit hebben mensen bijvoorbeeld gedaan in zelf gestichte kolonies; vandaar dat men hen als de kolonisten zou kunnen betitelen. Deze drie groepen hanteren geen geweld om het heilsrijk naderbij te brengen. Dat doet echter wel de vierde groep: de fanatici. Zij zijn ervan overtuigd dat God een handje moet worden geholpen of het geschied- 
verloop moet worden bespoedigd. Fanatici zijn dus voluntaristen: zij wachten niet af, maar leggen de geschiedenis hun wil op.

Waarom en hoe deze vierde groep dit doet, is onderwerp van dit artikel. Om de handelwijze van fanatici beter te begrijpen is het noodzakelijk de apocalyptische verhaalelementen in kaart te brengen.

\section{De ingrediënten van het apocalyptische verhaal}

Hoewel we verder in de tijd terug zouden kunnen gaan op zoek naar oerbronnen van het apocalyptische verhaal, is het uitgangspunt hier: het boek Openbaring, het laatste boek van de Bijbel, toegeschreven aan Johannes van Patmos, waarin we alle apocalyptische verhaalelementen aantreffen. Johannes dankt de toevoeging 'van Patmos' aan het feit dat de Romeinse machthebbers hem aan het eind van de eerste eeuw na Christus wegens zijn christelijke overtuiging naar dit eiland verbanden. Daarmee hebben we al dadelijk een van de kenmerken van veel auteurs van apocalyptische narratieven te pakken: het gaat vaak om sociaal uitgeslotenen, niet zelden mensen die gevangen zijn gezet. Zij voelen een sterke neiging om het degenen die hen op deze manier hebben vernederd betaald te zetten. Hun resten binnen de feitelijke of gedroomde gevangenis echter nog maar twee wapenen voor deze vorm van revanche: hun fantasie en het woord.

Zij gebruiken die wapens om hun persoonlijke vernedering te koppelen met een groep waaraan zij zich verwant voelen en die in hun ogen eveneens wordt vernederd. In het geval van Johannes waren dit de vervolgde christenen. Zijn boek was enerzijds bedoeld om die vervolgde christenen te troosten: aan het einde der tijden zullen de laatsten van nu de eersten worden en de eersten van nu - de ongelovigen, de machthebbers, de rijken - zullen de laatsten worden. En er is nog een troost voor de onderdrukten: hoe nijpender hun omstandigheden, des te spoediger zal de eindtijd een aanvang nemen. Daarvoor moet eerst nog wel slag worden geleverd tussen de krachten van goed en kwaad. Omdat de goeden God aan hun zijde hebben, zullen zij uiteindelijk winnen. En de vroegere heersers en machtigen zullen branden in de hel. Het einde der tijden brengt dus niet een soort egalitaire samenleving. Fanatici gaan altijd uit van een paradijs voor hun groep. De anderen kunnen niet genoeg lijden. Leedvermaak over hun lot viert vaak hoogtij in apocalyptische geschriften als dat van Johannes van 
Patmos. In dit verband wordt ook wel de term 'apocalyptische jouïssance' gehanteerd (Eagleton 2005, p. 111). Tegelijk mag Johannes in het boek Openbaring een blik vooruitwerpen op deze heilsstaat, een soort hemelse sightseeing. Ook dit element van een soort Mozes, die vanaf een berg het beloofde land van de toekomst ziet, komt in veel apocalyptische verhalen voor.

Dit heeft een specifieke functie. Apocalyptische vertellers plaatsen de wereld van nu, dat wil zeggen de wereld van het onrecht, tegenover een ideale wereld waarin gerechtigheid heerst. In het geval van het Bijbelboek Openbaring brengt God die gerechtigheid door, gesteund door de ware gelovigen, eerst de strijd tegen het kwaad aan te gaan en vervolgens op de dag des oordeels de schapen van de bokken te scheiden. Elke religie kent zo'n onderscheid tussen de reële wereld en de ideële wereld, maar apocalyptische fanatici maken deze spanning tussen onrecht en gerechtigheid zo groot dat het immoreel wordt om niet die reële wereld kort en klein te slaan, zodat er ruimte ontstaat voor de nieuwe ideële wereld.

Deze strijd tussen goed en kwaad is binair: er is geen plaats voor een tussenstroming. Zo mogelijk nog krachtiger dan tegen de kwaden van de aarde gaat Johannes tekeer tegen de neutralen of 'lauwen'. Onverschilligheid is apocalyptische fanatici een doorn in het oog. Zo ontstaat een zeer scherpe wij-zij-tegenstelling. En hoe groter de (betuigde) liefde voor de eigen groep, des te groter is de haat jegens de anderen, die immers in de weg staan aan de voltrekking van de gerechtigheid waarop de ware gelovigen en onderdrukten aanspraak maken.

\section{Apocalyps in Europa}

In het voorafgaande vielen de termen ware gelovigen en onderdrukten min of meer samen. Dit is begrijpelijk in de context waarin Johannes van Patmos zijn Bijbelboek schreef. Christenen werden achtergesteld en vervolgd in het Romeinse Rijk, al was dat niet zo hevig ten tijde van Johannes als hij ons wil doen geloven. Als de christenen zouden leven volgens de regels zoals Johannes die zag, mochten zij geen gebruik maken van het geld van de Romeinen, die op hun munten de keizer als een goddelijke figuur afbeeldden. Aldus ontstond een tegenstelling tussen enerzijds macht, rijkdom en het verkeerde geloof en anderzijds 
machteloosheid, armoede en het ware geloof, waarbij de laatsten uiteindelijk zouden winnen. Het verhaal van Johannes beloofde wat we vandaag de dag empowerment zouden noemen. Door deze tegenstelling van een injustice frame en een justice frame was het verhaal van Johannes dus niet een zuiver religieus verhaal, maar tegelijk een verhaal waar een subversieve werking van kon uitgaan op de bestaande aardse machtsverhoudingen. Toen later in het Romeinse Rijk de christelijke kerk min of meer staatskerk werd, spanden kerkvorsten zich dan ook in om een subversieve, aardse uitleg van Openbaring de kop in te drukken. Dit lukte tot aan de dertiende eeuw.

Daarna volgden enkele eeuwen waarin met regelmaat gewelddadige apocalyptische bewegingen de kop opstaken in Zuid-, West- en Midden-Europa, bijvoorbeeld in het Italiaanse Florence eind vijftiende eeuw onder leiding van de dominicaanse monnik Savonarola. Een ander voorbeeld zijn de taborieten, die in de eerste helft van de vijftiende eeuw in Bohemen religieus-extremistische opvattingen paarden aan strategisch vernuft, waardoor zij vijandelijke legers lange tijd de baas waren. Strategisch inzicht was niet de sterke kant van Thomas Müntzer, die zich met zijn apocalyptische verwachting aan het hoofd van een boerenleger plaatste tijdens de Duitse Boerenoorlogen en in 1525 een smadelijke nederlaag leed in de slag van Frankenhausen. Het beste voorbeeld is waarschijnlijk de bezetting van de stad Münster gedurende 1534 en de eerste helft van 1535 door voornamelijk uit de Lage Landen afkomstige Wederdopers. Zij verwachtten dat in deze stad het nieuwe Jeruzalem zou neerdalen, wat het begin van de eindtijd zou betekenen.

Wat veel van deze bewegingen gemeen hadden, was hun kritiek op de traditionele kerk, die in haar streven naar wereldlijke macht en rijkdom in de ogen van de critici eerder een antichrist dan een vertegenwoordiger van God op aarde was geworden. De nieuwe geloofsovertuigingen werden vaak verkondigd door monniken en priesters die zelf in conflict waren gekomen met de kerk, maar ook door lekenpriesters. De opkomst van de boekdrukkunst speelde eveneens een belangrijke rol. Zonder tussenkomst van de traditionele clerus gingen gelovigen nu zelf de Bijbel uitleggen in de landstaal en zij vonden een nieuw gehoor, dat gedeeltelijk zelf geletterd was. Daarmee was er een cocktail van verwarring over de juistheid van de bestaande verhoudingen, nieuwe geestelijke leiders, een nieuw medium en een nieuw gehoor, die een goede voedingsbodem vormt voor apocalyptische bewegingen. 


\section{De ideologische apocalyps}

Na 1700 verdween het apocalyptische gedachtegoed niet volledig uit West-Europa, maar de gewelddadige variant manifesteerde zich nu hoofdzakelijk in ideologische vorm. Het ging daarbij om zingevingssystemen waarin het transcendente niet langer aanwezig was, of zoals dat wel genoemd wordt: 'God was taken out of the equation' (Kiersey \& Stokes 2011, p. 126). Dat betekende overigens niet dat ideologieën en de tenuitvoerlegging daarvan geen religieuze elementen meer konden bevatten. Sommige van de hierna te behandelen stromingen als het communisme of het nationaalsocialisme zijn daarom ook wel getypeerd als 'political religion' (Burrin 1997; Gentile 2005). Ironisch is dat de verlichtingsfilosofen wilden afrekenen met het (religieuze) fanatisme, maar een aantal van hen juist ruimte schiep voor een nieuwe vorm van fanatisme. Een belangrijke bijdrage daartoe leverde Jean-Jacques Rousseau, die streefde naar een ideale burgergemeenschap, die zou afrekenen met de oude instituties, maar waarin geen plaats zou zijn voor burgers die zich niet aan het gemeenschappelijk sociaal contract zouden houden. Hij was bovendien een groot voorstander van transparantie.

Zo'n vijftien jaar na de dood van Rousseau werd Robespierre als het ware de executeur-testamentair van Rousseaus gedachtegoed. De Franse Revolutie schiep een ideologie van gelijkheid onder de Franse patriotten, waarbij Robespierre kwam bovendrijven als degene die retorische gave koppelde aan een rücksichtslose wil de revolutie voort te drijven en verdedigen. De groep van de contrarevolutionairen en 'lauwen' werd daarbij steeds groter en die van de 'goeden', dat wil zeggen de ware Franse patriotten, steeds kleiner. Totdat ten slotte Robespierre zelf ten prooi viel aan dit onderscheidend mechanisme en met zijn hals onder de guillotine belandde.

De negentiende eeuw gaf vooral in Rusland een voortdurende combinatie van revolutionair elan en heilstijdverwachting te zien. Een tegenwoordig nauwelijks meer bekende, maar in zijn tijd onder studenten uiterst populaire schrijver was Nikolaj Tsjernysjevski. Zijn roman Wat te doen? werd een grote inspiratiebron voor tal van Russische revolutionairen, onder wie Lenin. In de roman, die hij in gevangenschap schreef, schetste Tsjernysjevski hoe een soort supermensen toe werkten naar een revolutie. Een bekend onderdeel uit zijn roman is de vierde droom van Vera Pavlovna, een van de hoofdrolspelers uit het 
boek, waarin zij - heel apocalyptisch - een kijkje krijgt in de ideale wereld, die na de revolutie zal ontstaan.

Een andere belangrijke ideologische apocalyptische stroming was het nationaalsocialisme. Het was een antwoord op de grote vernedering die veel Duitsers voelden na het verliezen van de Eerste Wereldoorlog. Wie dit gevoel van verwarring goed wil leren kennen, moet er de dagboeken van Goebbels uit de jaren twintig van de vorige eeuw op naslaan (Bärsch 1995; 2002). Hij had, net als veel tijdgenoten, het idee dat de wereld op haar kop stond. In zulke tijden van Zusammenbruch maakt een nieuwe wereldbeschouwing in de vorm van een apocalyptische opvatting een kans. In zijn dagboek noteerde Goebbels in zuiver apocalyptische stijl de smeekbede: 'Heer, toon het Duitse volk een wonder! Eén man!!!' (in: De Graaff 2012, p. 400). Uiteindelijk vond Goebbels zijn heiland in Hitler en diens beweging die het Derde Rijk aankondigde. Een deel van de Duitse clerus ging moeiteloos mee met het nationaalsocialisme, maar andere leiders stonden er handenwringend bij en vroegen zich af waarom het nationaalsocialisme met zijn heilsaanspraken zoveel meer wervende kracht had dan het woord Gods, zoals zij dat verspreidden (De Graaff 2012, p. 405-406). Ook dit is een verschijnsel dat niet ongebruikelijk is bij een apocalyptische beweging: traditionele geestelijke leiders die zien hoe de apocalyptische nieuwlichters en hun narratief hen buitenspel plaatsen bij een breed publiek.

\section{Selffulfilling paranoia}

Wie meent dat na de verlichting de gedachte aan een (gewelddadige) apocalyps geheel is verdwenen, vergist zich. In de Verenigde Staten is de gedachte dat het einde der tijden nog tijdens het eigen leven zal komen wijdverbreid. Geregeld trekken christelijke milities zich terug op boerderijen of in eigen gemeenschappen en wapenen zich voor het grote gevecht aan het einde der tijden. Gealarmeerd door de opeenhoping van wapens, soms in combinatie met geruchten over kindermisbruik, komen de autoriteiten dan letterlijk in het geweer, en stevig ook, omdat de verwachte weerstand groot is. De apocalyptici die deze overmacht zien naderen, zien daarin weer een bevestiging dat het einde der tijden nu daadwerkelijk is aangebroken met de komst van de heerscharen van het kwaad. Daarom wordt wel gesproken van een 'selfful- 
filling paranoia' (Barkun 1974, p. 151-152), een verschijnsel dat de verhouding tussen apocalyptici en hun bestrijders goed illustreert. De autoriteiten hebben de indruk dat met de apocalyptici niet te praten valt, dat zij op een andere golflengte zitten, en dat, in het licht van hun dreiging, een gewelddadige confrontatie de enige uitweg is. Voor de apocalyptici is deze confrontatie het bewijs dat zij van stonde af aan gelijk hadden; daarom lokken zij zo'n confrontatie ook min of meer uit.

Dit is ook vaak de essentie van populaire voorstellingen van de apocalyps, zowel in christelijk Amerika als in het islamitische Midden-

Oosten. In de Verenigde Staten hebben de afgelopen decennia romantische vertellingen over het einde der tijden herhaaldelijk miljoenenoplagen gehaald. In deze romans worden Bijbelcitaten telkens vertaald naar een actuele situatie. Troepen van de antichrist werden jarenlang gelijkgesteld aan Sovjetlegers. Na de Koude Oorlog werd het ultieme kwaad in dit soort romans de islam. De islamitische heiland, de Mahdi, werd in deze voorstellingen de antichrist.

Zo spiegelen christelijke en islamitische eindtijdverwachtingen zich aan elkaar. Populaire islamitische voorstellingen gebruiken niet zelden westerse elementen. Zo kan men lezen dat de islamitische antichrist huist in de Bermudadriehoek, zich verplaatst met een ufo en de steun heeft van vrijmetselaars. Ter legitimering van het eigen eindtijddenken wordt een beroep gedaan op Amerikaanse televisiedominees of voormalig president Reagan. Veel van de populaire islamitische voorstellingen van het einde der tijden laten hun verhaal eindigen met een opstomen van de Amerikaanse vloot in de Middellandse Zee, waarna een nucleaire confrontatie plaatsvindt, die op miraculeuze wijze leidt tot de zege van de islam over de hele wereld en een soort paradijs in Jeruzalem (Cook 2002; Filiu 2008).

\section{Al Qaida en IS}

Tegen deze achtergrond is het niet verbazingwekkend dat bij sommige moslims het idee opkwam dat Osama bin Laden misschien de Mahdi was. Osama bin Laden heeft die gedachte altijd verre van zich geworpen (De Graaff 2012, p. 562-565). Hij zag zichzelf nooit als een eindtijdfiguur en meende dat de beweging ook na hem zou moeten voortbestaan. Hij zag zichzelf slechts als een martelaar langs de weg die uit- 
eindelijk naar herstel zou leiden van het kalifaat, dat in 1924 teloor was gegaan. Dat kalifaat was slechts een vergezicht en had bij Bin Laden voornamelijk een retorische functie. Dat kwam mede door een leerstellig probleem dat Bin Laden had. Hij stond in de traditie van de peetvader van het islamisme, de Egyptenaar Said Qutb. Qutb had in zijn uit de gevangenis gesmokkelde geschriften betoogd dat er slechts één was die over moslims kon heersen: Allah. Wie zich islamitische heerser noemde, was volgens Qutb per definitie geen goede moslim (De Graaff 2012, p. 503-521). Deze opvatting kwam goed van pas zolang islamisten erop uit waren regimes in het Midden-Oosten aan de kaak te stellen en omver te werpen. Maar deze opvatting stond tegelijk de opbouw van een nieuwe staat of kalifaat in de weg. Bin Laden en andere islamisten bleven daardoor het antwoord op de vraag hoe hun nieuwe samenleving eruit zou zien schuldig. Veel verder dan het idee dat daar de sharia zou heersen, kwamen ze niet.

Dit was anders bij de mensen die aan de oorsprong stonden van IS, zoals al-Zarqawi. Zij gingen ervan uit dat waar twee moslims bijeen waren er één de sjeik of de emir was (De Graaff 2015, p. 49). Daarmee was hiërarchie en dus heerschappijuitoefening in een staat mogelijk. Terwijl Bin Laden had gepleit voor een geleidelijke totstandkoming van een kalifaat, voerde een van de opvolgers van al-Zarqawi, al-Baghdadi, het kalifaat in. 'Overhaast', zou Bin Laden hebben gezegd, als hij nog had geleefd, net zo goed als hij bij leven kritiek had gehad op alZarqawi en de zijnen wegens het extreme geweld dat zij gebruikten. Volgens Bin Laden en zijn adjunct en latere opvolger al-Zawahiri zouden door dit extreme geweld moslims van de beweging worden vervreemd en de geleidelijke groei onmogelijk zijn. Bin Laden en de zijnen kwamen intussen niet veel verder dan de anarchisten rond 1900: zij probeerden wel de oude wereld te vernietigen, maar bereikten bar weinig in het scheppen van een nieuwe.

De voluntaristen van IS zagen daarentegen hoe hun strategie, in elk geval aanvankelijk, veel succes boekte. Dankzij de uitroeping van een kalifaat was er nu een grondgebied waar daadwerkelijk de sharia kon worden toegepast en waar moslims niet langer het gevoel hoefden te hebben te midden van zonde te leven. Bovendien konden zij hier hun slachtofferrol kwijtraken. Er was sprake van 'empowerment': slachtoffers werden daders, gesymboliseerd in onthoofdingen van westerse slachtoffers gekleed in de oranje overalls die islamisten in het Amerikaanse gevangenkamp Guantanamo Bay moesten dragen. 
Alle centrale elementen uit apocalyptische narratieven treft men aan bij IS: het idee van een eindstaat, in de vorm van het kalifaat, waar gerechtigheid heerst omdat moslims er zichzelf zouden kunnen zijn en hun leven wordt geregeld door de sharia, alsmede een scherpe wijzij-tegenstelling, waar christenen, sjiieten, jezidi's en anderen het slachtoffer van worden in het kalifaat. Het feit dat de rollen zijn omgedraaid tussen slachtoffers en daders, tussen eersten en laatsten, wordt verbeeld met ensceneringen van onthoofdingen, waarbij westerse slachtoffers gekleed zijn in het type oranje overalls dat de islamitische gevangenen op Guantanamo Bay werden gedwongen te dragen. De heerschappijuitoefening is dan ook totalitair en roept herinneringen op aan eerdere uitingen van apocalyptische machtsuitoefening, van de wederdopers in Münster tot aan het Derde Rijk van de nationaalsocialisten. Tegenslagen deren hun niet, want dit zijn uitsluitend beproevingen, maar met Allah aan hun zijde zullen zij de finale slag winnen.

Voor sommige moslims in het Westen die zich achtergesteld voelden, ging hier een sterke lokroep van uit. Traditioneel trekken interne gewapende conflicten buitenlandse strijders aan met het appel dat zij doen om de eigen gemeenschap, die in het gedrang is, te komen helpen (Malet 2013). Om die reden trok het conflict in Syrië al vóór de uitroeping van het kalifaat velen die zich identificeerden met het lot van de broeders en zusters in de Levant. Maar nu vond er de meest wereldhistorische gebeurtenis plaats die een mens zich kon indenken: het einde der tijden, en men kon bij de eindstrijd betrokken zijn. 'Don't miss the boat', was in essentie de leus waarmee IS via de (sociale) media rekruten trok (De Graaff 2015, p. 50). Wie aan de strijd zou deelnemen, zou bovendien zijn zonden worden vergeven. In feite werd nu een uitvergroting van het klein criminele bestaan mogelijk gedekt door de vroomheid van het doel. Het was een soort rapperideaal: je gedroeg je weliswaar misdadig, maar 'ergens' was wat je deed heel nobel. IS buit het apocalyptische element op tal van manieren uit, bijvoorbeeld via het eerder genoemde glossy internettijdschrift met de naam Dabiq, de plaats in Noord-Syrië waar zich de finale strijd tussen goed en kwaad zal afspelen. De twitterapp van IS droeg de naam 'the dawn of glad tidings'. De aan IS verwante beweging Jabhat al-Nusra doet in dit opzicht niet onder voor IS en heeft een mediakanaal met de naam al-Manara al-Bayda of 'de Witte Minaret', een verwijzing naar de plek ten oosten van Damascus, waar volgens moslims aan het einde der tij- 
den Jezus zal neerdalen om de strijd aan te binden met de krachten van het kwaad. Het hele gebied van Bilaad al-Shaam is trouwens in de islamitische verwachting de regio waar de finale strijd gevoerd gaat worden aan het einde der tijden (De Graaff 2013). De geografische nabijheid van Jeruzalem, waar niet alleen veel moslims, maar ook christenen en joden hopen het einde der tijden mee te maken, verhoogt de apocalyptische extase nog.

\section{Slot}

IS maakt dus gebruik van een duizenden jaren oud apocalyptisch concept, waarvan de ingrediënten in de vorm van een aantal verhaalelementen voorhanden zijn. Om aanhang te verwerven moeten apocalyptici telkens opnieuw met die ingrediënten een nieuw recept samenstellen dat aangepast is aan de vereisten van een nieuwe tijd en nieuwe omstandigheden. De leiders van IS zijn daarin geslaagd. Ze hebben stappen gezet die de leiding van $\mathrm{Al}$ Qaida niet durfde of kon zetten: extreem geweld tegen andere moslims, in het bijzonder de sjiieten, en de oprichting van het kalifaat. Daarmee hebben ze een veel breder geweldspalet tot hun beschikking gekregen dan de incidentele terroristische aanslagen waarin Al Qaida grossierde. In tegenstelling tot de verwachtingen van Osama bin Laden, die een zekere geleidelijkheid bepleitte, bleek de extreme geweldsuitoefening door IS juist veel aantrekkingskracht te hebben: het bleek een vorm van empowerment die de laatsten de kans bood de eersten te worden. Bovendien creëerde het kalifaat een wereldhistorisch moment, dat appelleerde aan een gevoel van 'don't miss the boat'.

Tegelijk vormt IS in zijn apocalyptische verschijningsvorm een overtreffende trap ten opzichte van eerdere manifestaties van gewelddadig eindtijdgeloof. Waar vroegere apocalyptische bewegingen meenden dat het nieuwe Jeruzalem in de eigen omgeving (Münster, Londen, enz.) een plaats zou vinden, is de blik nu gericht op het reële Jeruzalem. Terwijl eerdere apocalyptici slechts konden dromen van een daadwerkelijke destructie van de wereld, komt deze mogelijkheid voor de apocalyptici van IS een stuk dichterbij. Het experimenteren met aanslagen met gifgas is een onheilspellende voorbode, al blijft een atoomwapen, het ideale wapen in romantische apocalyptische voorstellingen, nog buiten bereik. Een sombere les uit het verleden is dat 
de bestrijders van apocalyptici eveneens vaak met fors geweld zijn opgetreden, al dan niet uitgelokt. Dit roept een schrikbeeld op van een eventuele interventie op de grond in Syrië.

Het alternatief is een cordon te leggen rond dit nieuwe kalifaat, met alle consequenties voor degenen die tegen hun wil daarin verblijven. Dat is voor hen bepaald geen prettig vooruitzicht, want IS laat als zoveelste apocalyptische beweging in de geschiedenis zien dat wat begint als een roep om gerechtigheid gemakkelijk ontaardt in ressentiment en wraakneming.

\section{Literatuur}

\section{Bärsch 1995}

C.-E. Bärsch, Der junge Goebbels. Erlösung und Vernichtung, Grafrath: Klaus Boer Verlag 1995.

\section{Bärsch 2002}

C.-E. Bärsch, Die politische Religion des Nationalsozialismus. Die religiösen Dimensionen der NSIdeologie in den Schriften von Dietrich Eckart, Joseph Goebbels, Alfred Rosenberg und Adolf Hitler, München: Wilhelm Fink 2002.

\section{Barkun 1974}

M. Barkun, Disaster and the millennium, New Haven: Yale University Press 1974.

\section{Burrin 1997}

Ph. Burrin, 'Political religion. The relevance of a concept', History \& Memory (9) 1997, afl. 1/2, p.

321-349.

\section{Cohn 1970}

N. Cohn, The pursuit of the millennium, Oxford/New York:

Oxford University Press 1970.

\section{Cook 2002}

D. Cook, Studies in Muslim apocalyptic, Princeton, NJ: The Darwin Press 2002.

\section{Eagleton 2005}

T. Eagleton, Holy terror, Oxford: Oxford University Press 2005.

\section{Filiu 2008}

J.-P. Filiu, L'apocalypse dans

l'Islam, Parijs: Fayard 2008.

\section{Gentile 2005}

E. Gentile, 'Political religion: A concept and its critics - A critical survey', Totalitarian Movements and Political Religions (6) 2005, afl. 1, p. 19-32.

\section{De Graaff 2012}

B.G.J. de Graaff, Op weg naar Armageddon. De evolutie van fanatisme, Amsterdam: Boom 2012.

\section{De Graaff 2013}

B.G.J. de Graaff, 'De grote slachting. Derde Wereldoorlog of apocalyps in Syrië', De Groene Amsterdammer 4 december 2013. 


\section{De Graaff 2015}

B.G.J. de Graaff, 'How to keep our youth away from IS: The need for narrative analysis and strategy', Journal of Strategic Security (8) 2015, afl. 3, p. 48-52, http:// scholarcommons.usf.edu/jss/ vol8/iss5/5/.

\section{Gray 2007}

J. Gray, Zwarte mis. Apocalyptische religie en moderne utopieën, Amsterdam: Ambo 2007.

\section{Halverson e.a. 2013}

J.R. Halverson, H.L. Goodall, Jr. \& S.R. Corman, Master narratives of Islamist extremism, New York: Palgrave Macmillan 2013.

\section{Kiersey \& Stokes 2011}

N.J. Kiersey \& D. Stokes, Foucault and international relations. New critical engagement, Londen/ New York: Routledge 2011.

\section{Malet 2013}

D. Malet, Foreign fighters. Transnational identity in civil conflicts, Oxford: Oxford University Press 2013.

\section{McCants 2015}

W. McCants, The ISIS apocalypse. The history, strategy, and doomsday vision of the Islamic State, New York: St Martin's Press 2015. 